\title{
El Impresionismo en Bogotá: la crítica de arte a finales del siglo XIX desde la obra de Andrés de Santa María
}

\author{
Impressionism in Bogota: art criticism towards the end of the 19th century \\ through Andrés de Santa María's oeuvre
}

\section{María Toro Molinares}

Colegio Mayor de Nuestra Señora del Rosario

mariaau.toro@urosario.edu.co

Fecha de recepción: 15 de agosto de 2019

Fecha de aprobación: 7 de diciembre de 2019

\begin{abstract}
Resumen
El presente artículo identifica los fundamentos teóricos y conceptuales de la crítica de arte de finales del siglo XIX y comienzos del siglo XX en Colombia, haciendo énfasis en la prensa cultural capitalina. Así mismo, proporciona una definición del concepto de "Arte" para finales del siglo XIX y una reseña detallada de los criterios de valoración de dicho arte. Finalmente, se busca entender el rol del crítico de arte, a partir del estudio de caso de la "Polémica del Impresionismo" en Bogotá (1899-1904).
\end{abstract}

Palabras clave: Arte, Crítica de arte, Impresionismo, Prensa cultural.

\begin{abstract}
This article identifies the theoretical and conceptual foundations of art criticism of the late 19th century and early 20th century in Colombia, emphasizing in the capital's cultural press. Likewise, it provides a definition of the concept of "Art" at the end of the 19th century and a detailed review of the criteria for the valuation of said art. Lastly, this article seeks to understand the role of the art critic, from the case study of the "Controversy of Impressionism" in Bogotá (1899-1904).
\end{abstract}

Keywords: Art, Art Criticism, Impressionism, Cultural press. 


\section{Introducción}

El arte colombiano a mediados del siglo XIX se caracterizó por la disolución de cánones estéticos coloniales y la constitución de imaginarios nacionales, a partir de la creación de una Academia de Bellas Artes en $1886^{1}$. Así pues, dicho arte se presentó como un medio idóneo para la materialización de los ideales civilizatorios de la élite política, al ilustrar alegóricamente a los héroes de la patria, las grandes batallas nacionales y el territorio. Además, las nuevas tendencias se encargaron de conceptualizar la modernidad o por lo menos darle una apariencia. De esa forma, las imágenes sobre el Antiguo Régimen colonial fueron reemplazadas por símbolos nacionales alusivos a los intereses políticos dominantes².

En términos estéticos, la iconografía de este periodo se articuló con la profesionalización de los artistas ${ }^{3}$. Esto posibilitó el estudio exhaustivo de la técnica y la teoría, facilitando la instauración de parámetros evaluativos o clasificatorios del arte, entre ellos el manejo de la mimesis, la perspectiva, la anatomía, la geometría, los colores y el dibujo ${ }^{4}$. Estos primeros intentos formales, actualmente pueden ser calificados como carentes de "habilidad", pues eran representaciones esporádicas simples ${ }^{5}$. No obstante, dicha "incapacidad" también es un aspecto llamativo de este tipo de arte, dado que es posible dar cuenta de un valor "fresco" de "autenticidad americana".

De igual modo, estas obras de origen civil y republicano contenían ideales expresivos del "romanticismo provinciano", el cual buscaba un equilibrio entre los paisajes "objetivos" del territorio, los gustos públicos y la conciencia artística, es decir, los cánones estéticos de la Academia ${ }^{6}$. Así pues, desde las reflexiones estéticas sobre los principios y las prácticas del arte formal, a finales del siglo XIX, se dio paso a las primeras propuestas de crítica de arte a nivel nacional, si bien eran apenas breves reseñas periodísticas sobre las Exposiciones Anuales, los Salones Nacionales de Artistas y las Ferias Artesanales e Industriales de la capital ${ }^{7}$. Incluso, en algunos casos, dentro de la prensa local se escribía sobre una obra o artista en particular.

Sin embargo, con el tiempo esta crítica empezó a ser elaborada por artistas, escritores e ilustrados dispuestos a valorar obras plásticas con relación al paradigma

1 Santiago Londoño, Pintura en América Hispana. Tomo II - Siglo XIX (Bogotá: Editorial Universidad del Rosario y Luna Libros, 2012), VII.

2 Santiago Londoño, Pintura en América Hispana. Tomo II - Siglo XIX (Bogotá: Editorial Universidad del Rosario \& Luna Libros, 2012), VII.

3 Carmen María Jaramillo, «"Una mirada a los orígenes del campo de la crítica de arte en Colombia”, Artes: La Revista 7 (2004): 6.

$4 \quad$ Víctor Quinche, Andrés de Santa María en los críticos de arte colombianos (Bogotá: Editorial Universidad del Rosario, 2014), 66.

5 Eugenio Barney Cabrera, "Reseña del arte en Colombia durante el siglo XIX", Anuario Colombiano de Historia Social y de la Cultura 3 (1965): 71.

6 Cabrera, "Reseña del arte en Colombia durante el siglo XIX", 83.

7 Jaramillo, "Una mirada a los orígenes", 9. 
visual vigente ${ }^{8}$. Dicho paradigma estaba construido a partir de los estándares proporcionados por el "modelo academicista", el cual era enseñado dentro de diversas escuelas o talleres de la capital. Con la misma relevancia, las obras expuestas en los Salones Nacionales de Artistas desde 1886 fueron esenciales para reafirmar los juicios de arte elaborados por dicha crítica ilustrada ${ }^{10}$. Es importante señalar que estas nociones rápidamente se sometieron a prueba, debido a la apertura de nuevas tendencias estéticas provenientes de Europa. Entre estas se encuentra el Impresionismo, el cual dio protagonismo a las impresiones de la realidad antes que a la mimesis de esta.

Este tipo de arte fue polémico para finales del siglo XIX en el territorio colombiano, específicamente en Bogotá, pues aparentemente no podía ser comprendido y mucho menos valorado bajo los presupuestos "tradicionales" ${ }^{11}$. Por tanto, el trabajo presentado por artistas con sensibilidades modernistas fue aceptado parcialmente, debido a muchas resistencias, dentro del espacio cultural nacional de aquel periodo. Uno de los mejores ejemplos de esta situación fue la recepción de algunas de las obras del artista Andrés de Santa María (1860-1945) en Bogotá a finales del siglo XIX. Varios de sus cuadros no pasaron desapercibidos por la crítica, puesto que causaron incomodidad en la opinión pública.

Algunos artículos de la prensa local, al intentar comprender la propuesta artística de Santa María, cuestionaron la esencia del Impresionismo, visto que era un estilo carente de belleza, técnica y verdad. En pocas palabras, se consideraba como un arte vacío que no cumplía con los ejes civilizadores de la alta sociedad conservadora de finales del siglo XIX. En esa medida, la recién estructurada crítica de arte, la cual se había limitado a comentarios descriptivos y poco complejos, se vio obligada a hacer frente a los controversiales y progresivos cambios dentro del espacio plástico colombiano. Para ello, algunos autores se remitieron a conceptos estéticos provenientes del modelo academicista, mientras que otros, simplemente, argumentaron y trataron de dar sentido desde sus subjetividades.

Teniendo en cuenta lo expuesto anteriormente, este artículo tiene como objetivo central identificar los fundamentos teóricos y conceptuales de la crítica de arte de finales del siglo XIX, haciendo énfasis en la introducción de nuevos paradigmas artísticos en el territorio nacional. Para esto, pretendo reconstruir como caso de estudio la "Po-

8 David Jiménez, Historia de la crítica literaria en Colombia (Bogotá: Universidad Nacional de Colombia y Colcultura, 1992), 11-12.

9 El "modelo academicista" mantenía un estilo neoclásico exaltando la antigüedad grecorromana. Este a su vez fue inspirado por los más altos institutos de arte en Europa, los cuales recreaban el clasicismo. De igual modo, había una pretensión de realidad como medio para llegar a la belleza clásica, aquella que era exacta e inteligible. Esto se profundizará más adelante. Melero José Enrique García, Arte español de la ilustración y del siglo XIX: Entorno a la imagen del pasado (Madrid: Ediciones Encuentro, 1998), 11.

10 Jaramillo, "Una mirada a los orígenes", 7.

11 Víctor Quinche, Andrés de Santa María en los críticos de arte colombianos (Bogotá: Editorial Universidad del Rosario, 2014), 55. 
lémica del Impresionismo" en Bogotá (1899-1904). Igualmente, para detallar dicha polémica busco centrarme en la trayectoria del artista colombo-belga Andrés de Santa María durante su estadía en Bogotá (1893-1911). Esto con el propósito de reconocer las obras que fueron el centro de debate de la prensa cultural. Así pues, me gustaría cuestionarme por la forma como los críticos de arte en Bogotá interpretaron las obras "impresionistas" expuestas por Andrés de Santa María en la Feria de Instrucción Pública en 1904.

Más allá de una reconstrucción iconográfica e iconológica de las obras presentadas por el artista, deseo enfocarme en los argumentos propuestos por los críticos de arte dentro de sus publicaciones de finales del siglo XIX y comienzos del siglo XX en Bogotá. De igual modo, intentaré determinar qué era aquello que se entendía por "Arte" a finales del siglo XIX, para así reconocer el rol del crítico de arte. Todos estos planteamientos los realizo desde el marco de la historia cultural, entendiendo los procesos sociales que hay detrás de un objeto o una práctica. En cuanto a la estructura del presente artículo, este consta de seis apartados.

En la primera parte, se presentará un breve recuento de las publicaciones académicas más recientes sobre la crítica de arte en Colombia a finales del siglo XIX, con relación a la obra de Andrés de Santa María. Lo anterior con el propósito de dar cuenta de los debates vigentes tras la temática abordada en el presente artículo. En segundo lugar, se explicarán los conceptos claves, con los cuales se piensa abordar el análisis central de la crítica de arte. Para esto, se toma como fuente principal la investigación realizada por el filósofo Víctor Alberto Quinche Ramírez, Andrés de Santa María en los críticos de arte colombianos (2014). En la tercera parte, se determinarán las fuentes significativas para el análisis mencionado.

En la cuarta sección, se pretende ubicar el espacio sociocultural de finales del siglo XIX a nivel nacional, haciendo hincapié en la capital. Esta contextualización busca caracterizar el arte colombiano del siglo XIX, para vislumbrar los fundamentos teóricos y estéticos de la crítica de arte. Así mismo, esta revisión es útil para interpretar el lugar de enunciación, tanto de la crítica como del artista Andrés de Santa María. En la quinta parte, se realizará el análisis central del caso de estudio, es decir la "Polémica del Impresionismo", a partir de la crítica de arte de finales del siglo XIX en Bogotá. Por último, se darán anotaciones finales sobre la recepción del arte "Impresionista" en Bogotá, abordadas desde la prensa cultural en el periodo previamente especificado.

\section{La Crítica de arte de finales del siglo XIX desde la obra de Andrés de Santa Maria: un breve balance historiográfico}

La crítica de arte, con relación a la obra de Andrés de Santa María, ha sido ampliamente abordada dentro de la historiografía colombiana. Por otro lado, en el campo de la historia del arte en Colombia, las pinturas de Santa María se han consolidado como 
puntos de varios debates críticos, ya sea por su técnica o por su propuesta "modernista" en el arte nacional de finales del siglo XIX. Uno de los estudios más relevantes ha sido elaborado por el historiador y crítico de arte Álvaro Medina. En su libro Procesos del arte en Colombia (1978), Medina reconstruye la carrera artística de Andrés de Santa María, resaltando sus periodos creativos y sus respectivos cuadros, a partir de un seguimiento detallado de los salones de artistas y la prensa cultural colombiana de la época.

Desde el campo de la historia de la crítica literaria, el profesor David Jiménez realizó en su libro Historia de la crítica literaria en Colombia. Siglos XIX y XX (1992) un panorama general de los críticos "modernistas" del siglo XIX. Entre dichos críticos, sobresalen los ilustrados implicados en la "Polémica del Impresionismo" y sus respectivas publicaciones. También señala aspectos sobre la percepción del arte moderno en Colombia a finales del siglo XIX. Finalmente, el argumento central de Jiménez consiste en explicar parte del rechazo que recibió la obra de Santa María por parte de una élite política capitalina, como una reacción a las tensiones entre el romanticismo conservador y el simbolismo liberal ${ }^{12}$.

Otro estudio destacado es el artículo "Una mirada a los orígenes del campo de la crítica de arte en Colombia" (2004) de la historiadora del arte Carmen María Jaramillo. En este escrito, la autora se cuestiona por los inicios de la crítica de arte en Colombia, haciendo hincapié en los procesos políticos de dicha época. Además, en dicho artículo, Jaramillo señala la relación existente entre el desarrollo del arte colombiano y los proyectos nacionales republicanos en términos de modernidad. Así pues, la autora argumenta que las posturas asumidas por la incipiente crítica de arte del país en esa época, en cierto modo, impidieron la formación de actitudes críticas sobre las tendencias modernizantes del cambio de siglo.

Como se mencionó anteriormente, una fuente fundamental para el presente artículo es el libro Andrés de Santa María en los críticos de arte colombianos (2014), del filósofo Víctor Alberto Quinche. Esta propuesta se presenta desde el campo de la estética de la recepción, pues su objetivo principal es reconstruir la obra de Santa María desde la lectura de los críticos colombianos de arte, los cuales publicaban artículos, reseñas y notas que tenían repercusiones en el público lector ${ }^{13}$. Por último, la investigación más reciente sobre este asunto ha sido elaborada por el crítico de arte y curador Halim Badawi, en su libro Historia URGENTE del arte en Colombia. Dos siglos de arte en el país (2019). Este libro puede ser considerado un trabajo de carácter revisionista el cual muestra, desde diversas perspectivas analíticas y críticas, los matices ocultos de la Historia del Arte en Colombia. En otras palabras, es una lectura desde el subalterno.

12 David Jiménez, Historia de la crítica literaria en Colombia (Bogotá: Universidad Nacional de Colombia y Colcultura, 1992), 85-90.

13 Víctor Quinche, Andrés de Santa María en los críticos de arte colombianos (Bogotá: Editorial Universidad del Rosario, 2014), XI. 
Así pues, Badawi dedica varios apartados al arte colombiano del siglo XIX, dejando de lado la historiografía tradicional, para vislumbrar aquellos procesos, artistas y obras que pasaron desapercibidos o fueron silenciados por la Historia. Simultáneamente, Badawi reinterpreta figuras centrales en la escena plástica del siglo XIX, con la finalidad de dar una mayor comprensión al impacto de sus respectivas obras. Entre aquellos personajes se halla el pintor Andrés de Santa María, el cual es presentado como un artista capaz de romper paradigmas desde su posición privilegiada e influyente en la élite nacional. Badawi también sustenta que la apertura hacia el arte moderno en Colombia se dio a partir de la cátedra de Paisaje en la Escuela de Bellas Artes de Bogotá a finales del siglo XIX ${ }^{14}$. Esta cátedra estaba dirigida por Santa María, donde sembró en sus estudiantes "la duda frente a la realidad" y los formatos tradicionales de lo "pintoresco, documental, científico y cartográfico"15. Terminando, Badawi aborda diversos debates sobre la vida y obra de Santa María, entre ellos su origen o relativa "colombianidad", su círculo familiar, sus redes sociales o de influencia, sus gustos y trayectoria como artista, sus motivaciones personales y su trascendencia en la historia del arte en Colombia.

En resumen, se puede decir que la obra de Andrés de Santa María ha sido estudiada en varios campos de investigación. Incluso, es posible afirmar que la problemática para el investigador social contemporáneo es saber organizar y seleccionar sus fuentes secundarias o bibliografía de apoyo. En términos generales, el material disponible es realmente amplio. No obstante, no se ha insistido lo suficiente en una propuesta analítica desde las "historias conectadas". A decir verdad, pienso que la investigación de Badawi es pionera dentro de este campo de análisis específico, el cual todavía debería ser explorado con aún más meticulosidad y detalle. Lo anterior tiene sentido cuando se piensa en Andrés de Santa María como un artista colombiano de finales del siglo XIX, el cual recibió una formación artística completa en Europa, al haber estado radicado gran parte de su juventud en Francia.

Por tanto, se puede suponer un proceso de intercambio de ideas o expresiones artísticas entre las tendencias extranjeras y nacionales de finales del siglo XIX. Además, desde una perspectiva más amplia, varios de los primeros críticos de arte de ese siglo también fueron educados según tradiciones europeas ilustradas. Por ello, los criterios o estándares que se utilizaron como principios para estructurar la Academia Colombiana de Bellas Artes se fundamentaron en presupuestos extranjeros los cuales, muy probablemente, se adaptaron y modificaron según las necesidades locales. Esto implicaría un proceso de hibridación con fines nacionalistas. En esa medida, sería llamativo plantearse una futura investigación desde los estudios de redes, considerando procesos de apropiación, transformación e hibridación de códigos culturales. También,

14 Halim Badawi, Historia URGENTE del arte en Colombia. Dos siglos de arte en el país (Bogotá: Editorial Planeta Colombiana, S.A., 2019), 61.

15 Badawi, "Historia URGENTE del arte en Colombia", 61. 
sería interesante establecer una conexión entre los argumentos locales proporcionados por la recién formada crítica de arte colombiana y otros debates o pensamientos críticos sobre el arte modernista en el continente americano a finales del siglo XIX. Así pues, se verificaría la existencia de posibles interacciones bidireccionales entre críticos de arte durante esa época. Lo anterior sólo sería visible si se encuentran vínculos entre críticos a través de una circulación de prensa o una posible correspondencia, y considerando el grado de conexión o aislamiento de estos agentes culturales, respecto de los grandes debates del campo artístico a nivel mundial.

\section{Crítica y recepción: una aproximación a la crítica del arte}

Para abordar adecuadamente el marco teórico de la investigación, es importante tener en cuenta dos conceptos previos fundamentales. Se debe iniciar por la idea de crítica, la cual en este caso será expresada desde el área de las artes. Esta puede ser entendida como un conjunto de prácticas racionales vinculadas con la estética y el gusto. De modo similar, la crítica puede ser definida a partir de "juicios de valor", los cuales adquieren sentido dependiendo del valor, tanto intrínseco como externo de una obra de arte ${ }^{16}$.

Estos valores se configuran de acuerdo con el trabajo humano y las técnicas aplicadas a la creación de una obra. Otros criterios útiles para determinar aquel valor son la conceptualidad y la percepción, puesto que un objeto se enmarca como Arte cuando genera algún tipo de reacción o experiencia estética en un espectador ${ }^{17}$. Ahora bien, la formación de juicios de valor, en algunos casos, se vincula con los "juicios de autoridad", en donde se rescata la propiedad de un trabajo ${ }^{18}$, mas no sus componentes estéticos, simbólicos, culturales e incluso históricos. En otras palabras, una obra recibe valor por el renombre de su autor, mas no por su singularidad como pieza dentro de un espacio plástico.

Lo anterior es problemático, pues pensar una creación artística sólo en términos de autoridad la reduce, prácticamente, a un compilado de objetos no dinámicos, donde se fija una clasificación y categorización de esta. No se puede interpretar la obra fuera de preconceptos elaborados con relación al estilo del artista. Por consiguiente, el presente artículo no hará reparo sobre este tipo de juicios de valor, pues nublan el análisis de las obras de arte seleccionadas como fuentes primarias. Por otra parte, los juicios de valor se deben construir teniendo en cuenta el diálogo entre arte y crítica histórica. Este vínculo dialéctico articula varios elementos, entre ellos los códigos culturales, el contexto y los respectivos componentes estructurales de un trabajo artístico, para así proporcionar un valor concreto ${ }^{19}$.

16 Alberto González, "En torno a la crítica de arte". Revista de extensión cultural 32-33 (1994): 16-17.

17 González, "En torno a la crítica de arte", 16.

$18 \quad$ Ibid., 16.

19 Ibid.,18. 
De cualquier modo, algunos académicos precisan la noción de crítica como "la producción de todo tipo de escritos reflexivos acerca del arte, desde la historia del arte hasta la estética" ${ }^{20}$. La crítica de arte en su sentido más amplio hace referencia a una serie de tradiciones "modernas" que buscan evaluar obras o conjuntos de obras de arte, por medio de escritos y publicaciones especializadas. Simultáneamente, a partir de dichas obras esta crítica pretende calificar y juzgar a un artista o un grupo de artistas en un salón de exposición ${ }^{21}$. Sin embargo, para este artículo se hará uso de aquel concepto desde un sentido más restringido. En otras palabras, se va a entender por crítica de arte el conjunto de actividades desempeñadas por un individuo conocedor $\mathrm{y}$ estudioso de las artes.

Ahora bien, este individuo no solo posee la "autoridad" en dicho campo, sino que ejerce y crea opinión en distintos medios de comunicación. Por lo general, esta opinión es garantizada a partir de la mediana difusión de escritos y textos en una red de prensa. En ese sentido, el segundo concepto a considerar es de la recepción, la cual se plantea desde la teoría estética de la recepción (1967). Por ello, este proceso es precisado como la aprehensión de códigos culturales contenidos dentro de una obra. Así pues, este acercamiento permite desvelar las funciones del "receptor", en la medida en que dicha obra pasa a ser vista como un producto cultural dispuesto al consumo de un determinado grupo de individuos ${ }^{22}$. Igualmente, esta noción de recepción permite comprender el efecto de un creación cultural sobre un observador, dado que este entiende los mensajes del artista por medio de una experiencia estética o un ejercicio de referencialidad ${ }^{23}$.

Es decir, la recepción se logra a través de dos canales: un contacto directo o una aproximación teórica. En ese caso, la "prensa cultural o ilustrada" es un espacio que posibilita la recepción desde el plano teórico. Este tipo de prensa puede ser definida como el conglomerado de publicaciones, reseñas, artículos, semanarios y revistas que abordan temáticas relacionadas con las artes, la música o el desarrollo de las ciencias. Es una prensa ilustrada, puesto que sus consumidores son un público letrado. Además, estos lectores poseen un cierto saber sobre las tradiciones y tendencias contemporáneas de las artes, por ende, son individuos que se deleitan con las críticas y valoraciones hacia una obra. Por otro lado, los textos críticos que presenta este tipo de prensa cultural pueden ser clasificados según su estilo y nivel de profundidad.

Siendo así, los textos críticos pueden ser comprendidos como el grupo de descripciones, formulaciones, juicios e interpretaciones que realiza un académico o cono-

\footnotetext{
20 Víctor Quinche, "La crítica de arte en Colombia: los primeros años." Historia Crítica 32 (2006): 276.

21 Víctor Quinche, "La crítica de arte en Colombia: los primeros años." Historia Crítica 32 (2006): 277.

22 Claudio Godoy Arenas. "Semiótica y teoría de la recepción: Los estudios literarios según Umberto Eco." UCMAULE - Revista Académica de la Universidad Católica del Maule 43 (2012): 35.

23 Pablo Tinio, "From Artistic Creation to Aesthetic Reception: The Mirror Model of Art", Psychology Of Aesthetics, Creativity \& The Arts 7, no. 3 (2013): 271.
} 
cedor de las artes sobre una obra en particular ${ }^{24}$. Estos textos no solo analizan tendencias y artistas, sino cualquier tipo de evento relacionado con el mundo de las artes ${ }^{25}$. Así pues, las publicaciones críticas se presentan en tres niveles de estudio. El primero es de carácter informativo, pues es una noticia o reseña descriptiva que intenta dar conocimiento "objetivo" sobre un acontecimiento artístico. Por lo general, en este tipo de texto se ejecutan "evaluaciones débiles" sobre una obra, es decir, juicios valorativos sin cargas semánticas ${ }^{26}$.

El segundo nivel es evaluativo, ya que la necesidad de informar es reemplazada por el deseo de influenciar o generar una percepción sobre una obra ${ }^{27}$. En otras palabras, estos textos solo buscan crear opinión sobre tendencias artísticas, a través de "evaluadores fuertes". Estos evaluadores son aquellos que poseen una carga semántica fuerte, dado que son juicios "buenos" o "malos" sin puntos medios ${ }^{28}$. Finalmente, el tercer nivel es el ensayo crítico o la monografía sobre un artista, obra o conjunto de obras $^{29}$. Usualmente, estos escritos son publicados a manera de libro o revista seriada, pues son largos, extensos y llenos de reflexiones. Además, manejan términos técnicos con el propósito de determinar como "buena" o "mala" una obra en específico.

De esa manera, se dará mayor relevancia en este artículo a los textos críticos de tercer nivel, ya que proporcionan más indicios sobre el estilo de pensamiento o el razonamiento lógico de los críticos de arte de finales del siglo XIX en Bogotá. Igualmente, estos escritos fuertes presentan de modo ordenado los argumentos a favor o en contra a una tendencia artística. Por ello, son ideales para encontrar los motivos de rechazo o aceptación hacia una nueva corriente en particular. Por último, los dos conceptos brevemente desarrollados en este apartado son esenciales para entender el dinamismo y las implicaciones de la crítica de arte en la recepción pública de una obra o artista.

\section{Breves planteamientos sobre la "prensa cultural" y la obra de Andrés de Santa María}

Como se había indicado en un principio, las fuentes primarias que han sido seleccionadas para este artículo son las reseñas que hicieron referencia a las obras presentadas por el artista Andrés de Santa María en algunas de las exposiciones del Salón Nacional de Artistas en Bogotá a finales del siglo XIX. Así mismo, estas publicaciones hicieron parte de la prensa cultural capitalina de aquel momento, es decir, fueron es-

24 Quinche, "La crítica de arte en Colombia", 277-278.

25 Quinche, "La crítica de arte en Colombia", 277.

26 George Dickie. Evaluating Art, Filadelfia: Temple University Press, 1988.

27 Quinche, "La crítica de arte en Colombia", 278.

28 George Dickie. Evaluating Art, Filadelfia: Temple University Press, 1988.

29 Víctor Quinche, "La crítica de arte en Colombia: los primeros años." Historia Crítica 32 (2006): 278279. 
critos elaborados por ilustrados dentro de medios no tan conocidos fuera de las élites. En términos más específicos, los siguientes artículos o publicaciones son las fuentes primarias que serán analizadas a profundidad:

Cano, F. (1903). “Andres Santa María”. Lectura y Arte, No.1, Medellín.

Grillo, M. (1905). "Psicología del impresionismo". Revista Contemporánea, Vol.2, No.1, Bogotá.

Hinestrosa, R. (1905). "El impresionismo en Bogotá". Revista Contemporánea, Vol.2, No.3, Bogotá.

Sanín, B. (1904). "El impresionismo en Bogotá". Revista Contemporánea, Vol. 1, No. 2, Bogotá.

Algunos de estos escritos se encuentran en la misma revista o serie, ya que son respuestas a debates sobre la "Polémica del Impresionismo" en Bogotá, entre diversas personalidades o "críticos" de arte de la época. Lo interesante de estas discusiones públicas es la percepción o identificación de las posiciones de los críticos frente a un arte relativamente "desconocido". Por otro lado, hay algunos textos directos de la prensa, los cuales solo tienen intereses descriptivos. No obstante, aquellas descripciones son valiosas pues utilizan calificativos aparentemente aleatorios para las obras "modernistas".

En general, son fuentes de fácil acceso, pues han sido recopiladas en revistas y algunos tomos bibliográficos. Además, su disponibilidad es abierta y se pueden estudiar en hemerotecas o fondos bibliotecarios, entre ellos la Biblioteca Luis Ángel Arango y la Biblioteca Nacional de Colombia. Aunque, se debe mencionar que la lectura de estas fuentes ha sido un poco compleja pues, a pesar de ser fuentes mecanografiadas, hay varias dificultades como la falta de organización de los volúmenes de las revistas dentro de los fondos documentales o hemerotecas y la falta de autoría en algunas de las publicaciones.

\section{Un contexto para la crítica de arte capitalina de finales del siglo XIX}

El arte colombiano del siglo XIX ha sido categorizado como "ingenuo" y carente de habilidad, pues se presentaron dibujos espontáneos con poca técnica. No obstante, aquella falta de conciencia artística y destreza es uno de los puntos centrales de este tipo de arte, ya que le otorga originalidad y autenticidad ${ }^{30}$. De igual manera, en el siglo XIX se configuró un arte con "pretensiones de veracidad y referencias a la belleza clásica" ${ }^{31}$, cualidades que aparecen como signos de una nación que desea encontrar su

30 Eugenio Barney Cabrera, "Reseña del arte en Colombia durante el siglo XIX". Anuario Colombiano de Historia Social y de la Cultura 3 (1965): 71.

31 Halim Badawi, Historia URGENTE del arte en Colombia. Dos siglos de arte en el país (Bogotá: 
propio lenguaje visual desde la adopción de principios extranjeros. Los géneros artísticos de este periodo en particular son variados, como el paisajismo, el romanticismo provinciano, el retrato, la pintura de género, la pintura heroica y los cuadros nacionalistas, centrados estos en una apología a las batallas independentistas.

Por ello, se puede decir que el arte decimonónico en Colombia dio cuenta de las transformaciones sociales, políticas, económicas y culturales del país. Además, las expresiones artísticas de la época se convirtieron en el sistema ideal para enseñar y comunicar los ideales de "progreso y civilización" que tanto profesaba la élite nacional ${ }^{32}$. Este arte tenía fines concretos y funcionalidades claras con respecto a los imaginarios de la república, donde la noción de belleza era una virtud esencial del hombre civilizado. En teoría, las artes eran vistas como la apertura a la modernización del reciente Estado nacional. Un ejemplo de ello es el género del paisajismo, ya que tiene distintas manifestaciones a lo largo del siglo XIX. En un primer lugar, dicha pintura del paisaje fue hecha por viajeros europeos, los cuales tenían la intención de documentar y describir el territorio observado ${ }^{33}$.

Estas representaciones fueron acogidas por el Estado, en la medida en que proyectaban tanto la belleza como el potencial de aquel territorio. Así pues, el paisajismo, en un principio, se planteó como una herramienta para la apropiación del espacio y su progresiva transformación productiva, de acuerdo con los ideales de progreso y desarrollo republicanos. Es decir, contenía elementos estéticos dignos de analizar e interpretar, pero se prefirió concebir como un artefacto sociopolítico. Otro aspecto importante es el deseo de realismo. Los paisajes debían imitar la naturaleza fidedignamente, ya que construían testimonios del hombre, en cuanto a sus trajes, costumbres, espacios y actividades ${ }^{34}$. En ese sentido, "Colombia se descubre a sí misma gracias a las 152 obras de los pintores de la comisión corográfica" 35 , los cuales ilustraron las diversas zonas del país junto con sus correspondientes expresiones culturales.

La Comisión Corográfica (1850-1859) fue dirigida por el italiano Agustín Codazzi, el cual, a partir de una amplia investigación y labor de campo con varios artistas, reunió una serie de imágenes sobre el paisaje colombiano y las costumbres locales ${ }^{36}$. Este proyecto ha sido de gran importancia para la historia del arte nacional, debido a que supuso un modelo visual del territorio y los miembros que componen dicho Estado en construcción. Igualmente, este tipo de arte paisajista dio paso a la formación de otra tendencia artística, el romanticismo provinciano. Este se fundamentó en la espon-

Editorial Planeta Colombiana, S.A., 2019), 51.

32 Badawi, "Historia URGENTE del arte en Colombia", 53.

33 Ibid., 58.

34 Cabrera, "Reseña del arte en Colombia durante el siglo XIX", 74.

35 Eugenio Barney Cabrera, "Reseña del arte en Colombia durante el siglo XIX". Anuario Colombiano de Historia Social y de la Cultura 3 (1965): 75.

36 Cabrera, "Reseña del arte en Colombia durante el siglo XIX", 79. 
taneidad de las representaciones de actividades civiles, es decir, alegorías a caudillos, militares e incluso escenas de grandes batallas ${ }^{37}$. Por ello, se puede hacer referencia a un arte artificial que ilustra eventos históricos de trascendencia nacional.

En segundo lugar, el paisajismo fue entendido como un cambio dentro de las temáticas establecidas por el canon estético colonial, dado que surge de una aproximación al naturalismo científico. En otras palabras, las pinturas del paisaje logran sustituir parte del arte religioso y los retratos coloniales ${ }^{38}$, fortaleciendo un nuevo "gusto visual" e impulsando un tipo de consumo artístico moderno entre las élites. De igual forma, aquella pintura del paisaje promociona el exotismo extranjero, dado que personas de distintas nacionalidades llegan al territorio con el fin de explorar y aventurarse por el mismo. En aquellos viajes, los pintores retrataron a las personas que ocupaban el espacio, haciendo énfasis en los diferentes oficios "tradicionales" 39 . Varias de estas obras fueron relevantes para construir una imagen internacional de la recién creada república, en términos sociales, económicos y políticos, permitiendo establecer lazos neocoloniales con otros Estados.

En definitiva, gran parte del arte en Colombia durante el siglo XIX fue un artefacto político con fines estratégicos claros, posibilitando conocer el territorio, para luego administrarlo como mejor fuera conveniente, según las pretensiones universales de "progreso y civilización". Adicionalmente, el arte del siglo XIX sostenía propósitos sociales, los cuales tenían relación con los discursos culturales originados por la élite nacional. Aquellos discursos aspiraban a una modernización de las costumbres y tradiciones desde la imagen, a partir de la afirmación de conductas deseables ${ }^{40}$. Bajo esa premisa, surge el género del retrato ${ }^{41}$, popular entre la élite capitalina, pues resaltaba el prestigio y la superioridad moral e intelectual de las familias acomodadas.

Para finales del siglo XIX, los retratos inmortalizaban figuras de relevancia política y económica, destacando rasgos físicos y morales desde los elementos de la composición. Estas obras se caracterizaron por el manejo de la perspectiva, la anatomía y la geometría, es decir, un arte de la perfección ${ }^{42}$. Lo anterior, en gran medida, se debe a la adopción del modelo academicista, el cual indaga por las representaciones de la be-

\footnotetext{
$37 \quad$ Ibid., 84.

$38 \quad$ Ibid., 71.

39 Ibid., 92.

40 Halim Badawi, Historia URGENTE del arte en Colombia. Dos siglos de arte en el país (Bogotá: Editorial Planeta Colombiana, S.A., 2019), 52.

41 En un principio, los retratos solían ser miniaturas elaboradas por dibujantes profesionales. Estas obras eran realizadas con precisión y cuidado, pues debían de mantener los detalles mínimos de las representaciones. Esta tendencia es llamativa, pues es una técnica que se remonta a la colonia. Sin embargo, esta perdura hasta el siglo XIX por el alto costo de la fotografía. Eugenio Barney Cabrera, "Reseña del arte en Colombia durante el siglo XIX". Anuario Colombiano de Historia Social y de la Cultura 3 (1965): 88.

42 Rubén Darío Ladino Becerra, "Primeros años de la Escuela Nacional de Bellas Artes de Colombia" (Tesis de maestría, Pontificia Universidad Javeriana, 2015), 96.
} 
lleza, la virtud y los aspectos sublimes o sagrados de los referentes grecorromanos ${ }^{43}$. El arte académico se introduce en la escena plástica a finales del siglo XIX como la "tendencia central" para los ilustrados capitalinos, dado que sus principios concuerdan con los planes de modernización cultural de la administración republicana. Por esto, el academicismo se prestó como un criterio de estandarización de las manifestaciones artísticas a nivel nacional. El conocimiento civilizatorio, acumulado y difundido en la capital, aparentemente llegó a las regiones del país a través de la enseñanza del arte académico, específicamente desde el retrato. En ese orden de ideas, dicho retrato se convirtió en un "espejo de clase" ${ }^{44}$, donde se enaltecía al hombre ideal, un miembro de la élite.

Bajo esta misma lógica, el retrato también puede ser analizado como una estrategia cultural asociada con el concepto de "colonialismo interno" 45 , pues benefició a la construcción de estereotipos desde el modelo visual del hombre "civilizado", perteneciente a la élite santafereña de finales de siglo. Estos fueron dañinos en la medida en que reafirmaron la idea de "fijeza" y "rigidez" dentro de un orden social inmutable ${ }^{46}$, garantizando la subordinación de diversos grupos sociales. A su vez, favorecieron a la creación de "otros", haciendo viable la distinción social entre entes "bárbaros" y "cultos". En otras palabras, el arte academicista no solo se autoproclamó un testamento del buen gusto, sino un arte abanderado del desarrollo cultural nacional, a costa de la segregación simbólica de la población.

Finalmente, es relevante indicar que el academicismo se apoyó constantemente en la Academia de Bellas Artes de Bogotá ${ }^{47}$. En esta Academia se enseñó el modo ideal de representación, es decir, el manejo de formas, colores, texturas y distribuciones espaciales. De manera adicional, se enseñó pintura aguada y al óleo, a partir de modelos en yeso y al natural ${ }^{48}$. Así pues, la Academia impuso con severidad los

43 Ladino, "Primeros años de la Escuela", 95.

44 Halim Badawi, Historia URGENTE del arte en Colombia. Dos siglos de arte en el país (Bogotá: Editorial Planeta Colombiana, S.A., 2019), 52.

45 La noción de "Colonialismo Interno" consiste en la permanencia y la renovación de estructuras coloniales dentro de Estados nacionales, en donde el dominio colonial es reemplazado por el dominio burgués. Así pues, se presentan relaciones de orden colonial, tales como, restricciones para los altos cargos políticos y militares, desigualdad en la repartición de bienes, regulación en los contenidos culturales y distinciones negativas sobre un grupo racial o minoría en particular. Pablo González Casanova, La teoría marxista hoy. Problemas y perspectivas (Buenos Aires: Consejo Latinoamericano de Ciencias Sociales, CLACSO, 2006).

46 Laura Catelli, "Pintores criollos, pinturas de castas y colonialismo interno: los discursos raciales de las agencias criollas en la Nueva España del periodo virreinal tardío" Cuadernos del CILHA 13, 2 (2012): 164 -165. 47 Esta fue fundada por el ilustre Alberto Urdaneta en 1886, se ubicó en el edificio San Bartolomé y conto con seis secciones, entre ellas Arquitectura, Escultura, Ornamentación, Dibujo, Pintura y Grabado en madera. El personal de enseñanza estaba capacitado en diversos ámbitos artísticos, siendo autoridades en la difusión de conocimiento. Rubén Darío Ladino Becerra, "Primeros años de la Escuela Nacional de Bellas Artes de Colombia" (Tesis de maestría, Pontificia Universidad Javeriana, 2015), 39 - 43.

48 Ladino, "Primeros años de la Escuela", 50. 
cánones estéticos y nuevas posibilidades de creación ${ }^{49}$, iniciando una etapa de profesionalización del artista. En otras palabras, el arte deja de ser una cuestión vinculada al oficio artesanal y el sistema gremial, para convertirse en una profesión ${ }^{50}$. Por otro lado, al plantearse como una disciplina, en teoría, el artista se torna virtuoso y seguro, ya que sigue leyes vigentes, evadiendo el desvío creativo.

Por ende, se hace alusión a una imitación de cuadros y tendencias europeas como el barroco o el realismo español ${ }^{51}$. Otro aspecto por señalar son las becas otorgadas por el Estado a estudiantes de la Academia $^{52}$. Las becas se dieron con el propósito de especializar los conocimientos técnicos de los asistentes a las cátedras, para generar frutos de "civilización" en su respectivo retorno del extranjero. Algunos países europeos fueron los destinos más comunes, entre ellos Francia, Inglaterra, Holanda, Bélgica e Italia ${ }^{53}$. Sin embargo, aquellos estudiantes becados, en estos nuevos contextos, se vieron expuestos a nuevas tendencias modernas, las cuales no pudieron emplear del todo en el territorio nacional.

Por ende, se debía escoger entre el arte experimental de carácter personal o el modelo establecido y respetado por la Academia. Esta cuestión se resuelve a partir del deseo de vivir del arte, ya que esto solo era posible si se perpetuaba el círculo de fórmulas arraigadas en la Academia. Al final, las tensiones entre el academicismo y las primeras tendencias modernistas no permitieron un cambio de paradigma inmediato. Por el contrario, fue un proceso lento y no lineal, ya que constantemente se dieron pequeños episodios de expresiones modernistas, pero que no llegaron a tener mayor resonancia. Para la Historia, se convirtieron en eventos marginales o "zonas grises" de este periodo en específico.

\section{La Polémica del Impresionismo: los retos de la crítica de arte a finales del siglo XIX}

Uno de los mayores aportes de la academia fue la promoción indirecta de la crítica de arte. Este fenómeno se originó principalmente en Bogotá. No obstante, hay rastros de una posible crítica en Medellín ${ }^{54}$. Esta crítica de arte fue calificada como "curiosa" y "anecdótica", en la medida en que algunos escritos y publicaciones no pasaban de la reconstrucción y descripción de eventos culturales. Así mismo, durante la segunda mitad del siglo XIX, la crítica se relacionó intrínsecamente con otras áreas culturales,

49 Eugenio Barney Cabrera, "Reseña del arte en Colombia durante el siglo XIX". Anuario Colombiano de Historia Social y de la Cultura 3 (1965): 107-108.

50 Rubén Darío Ladino Becerra, "Primeros años de la Escuela Nacional de Bellas Artes de Colombia" (Tesis de maestría, Pontificia Universidad Javeriana, 2015), 40.

51 Cabrera, "Reseña del arte en Colombia durante el siglo XIX", 108-109.

52 Ladino, "Primeros años de la Escuela", 76.

53 Cabrera, "Reseña del arte en Colombia durante el siglo XIX", 108.

54 Víctor Quinche, "La crítica de arte en Colombia: los primeros años." Historia Crítica 32 (2006): 275. 
entre ellas la literatura y la música. Por ello, las publicaciones críticas fueron ejecutadas por ilustrados o literatos no especialistas en las artes plásticas. Lo anterior posibilitó que se dieran confusiones, malentendidos e incluso discusiones públicas sobre el desarrollo de la cultura nacional ${ }^{55}$. Ahora bien, aquellos que realizaban crítica de arte tenían una gran relevancia dentro de la prensa cultural ilustrada.

Esto se explica puesto que el crítico es considerado como aquel que posee la autoridad suficiente para evaluar una obra pictórica. Simultáneamente, este evaluador califica la calidad de los cuadros con el propósito de dar cuenta de un avance o progreso dentro de la plástica nacional. En otras palabras, la crítica del arte en Colombia a finales del siglo XIX también tenía una función política, en la medida en que "reforzaba" los ideales de modernidad propios de las élites, a través de las expresiones culturales del país. Así pues, el arte era un canal dispuesto a medir el grado de desarrollo del nuevo estado nacional. En cuanto a la importancia social del crítico, se debe tener en cuenta que este se configura como un mediador entre las ideas del artista y las percepciones del público receptor ${ }^{56}$. Por ello, el crítico de arte desde sus publicaciones y escritos es capaz de orientar la recepción general de un artista dentro de la opinión pública.

Las primeras publicaciones fueron simples notas periodísticas, las cuales no esperaban guiar la experiencia estética de los observadores ${ }^{57}$. Por lo general, estas reseñas estaban orientadas a detallar las actividades de las exposiciones nacionales de artistas y los diferentes salones anuales, para así señalar los logros de la recién creada nación en términos culturales. Un aspecto curioso de estas exposiciones es la mezcla de objetos indígenas, productos industriales, obras de arte, música y artesanías ${ }^{58}$. Lo anterior responde a que los pabellones de las exposiciones se organizaban para mostrar los elementos que podían construir progreso e identidad nacional. Sin embargo, este último fin, desde la crítica del arte, no era tan evidente, pues esta se exterioriza como estática y renuente a las nuevas tendencias modernistas.

Así pues, con la aparición de aquellas tendencias en el territorio nacional, los críticos tuvieron que desenvolverse y modificar parte de sus juicios y criterios de valor $^{59}$. Un ejemplo de ello fue la crítica sobre la obra de Andrés de Santa María, la cual presentó al escenario plástico del país una serie de innovaciones técnicas y conceptuales según sus estudios en el extranjero. Actualmente, Andrés de Santa María es considerado como uno de los precursores del arte moderno en Colombia, e incluso de América Latina. Este inició su actividad como artista en París, Francia dentro del Salón Oficial de Artistas Franceses de 1887. Santa María fue uno de los pocos artistas colombianos en tener una educación integral en artes en Europa, especialmente en

\footnotetext{
$55 \quad$ Ibid., 276.

56 Víctor Quinche, "La crítica de arte en Colombia: los primeros años.” Historia Crítica 32 (2006): 280.

57 Quinche, "La crítica de arte en Colombia", 280

58 Ibid., 282.

59 Ibid., 290.
} 
Francia y Bélgica ${ }^{60}$. Así mismo, este tuvo contacto con las corrientes vanguardistas europeas de la segunda mitad del siglo XIX, entre ellas el Impresionismo ${ }^{61}$. En cuanto a su evolución como artista, Santa María comenzó dentro de un taller tradicionalista en la Escuela de Bellas Artes de París (1882).

Luego de ello, ingresó a la denominada "Academia Libre" o el taller de Henri Gervex (1887-1889), en donde aprendió algunas técnicas del naturalismo moderno. Igualmente, en aquella escuela aprendió una alternativa del realismo francés, la cual tiene principios impresionistas. Sin embargo, Santa María dentro de sus obras tiene una influencia realista y simbolista marcada ${ }^{62}$. Las obras que este artista realizó durante la década de 1880 se inclinaron al naturalismo con una cierta fractura en la temática, entre ellas se puede mencionar Los Fusileros (1885) y El Lavadero sobre el Sena (1887). Por el contrario, los cuadros que elaboró en la década de 1890 poseen una presencia más reconocida del Impresionismo. Entre dichos cuadros se pueden señalar Los Caballos (1894) y Las Segadoras (1895).

Ahora bien, Santa María llegó a Colombia a mediados de 1893. Este permaneció en el país por aproximadamente 17 años. Su estadía suele ser dividida en dos etapas por los historiadores del arte, puesto que dicho artista sale del país entre 1902-1903. Su primera etapa (1893-1901) estuvo marcada por la docencia, pues este se vincula con la Escuela de Bellas Artes de Bogotá en 1894 como catedrático de paisaje ${ }^{63}$. Las enseñanzas de Santa María causaron controversia a nivel local, pues intercambiaba conceptos realistas y simbolistas. En otras palabras, tenía un espíritu destructor frente a la tradición académica, pues buscaba experimentar con la estética colombiana ${ }^{64}$.

En esa medida, la "Polémica del Impresionismo" fue una serie de contestaciones públicas entre críticos de arte, sobre las obras expuestas por Andrés de Santa María en la Feria de Instrucción Pública de Bogotá en 1904. Entre los críticos que discutieron aquella exposición se encuentran Baldomero Sanín Cano, Ricardo Hinestroza Daza y Max Gri1lo. Para ese entonces, estos críticos eran identificados dentro de las élites sociopolíticas del país. Así mismo, eran figuras relevantes dentro de la prensa cultural, incluso, Sanín Cano era director de diversas revistas y publicaciones, como la Revista Contemporánea $(1904-1905)^{65}$. De igual forma, tanto Daza como Grillo participaban de las serializaciones de otras revistas a partir de comentarios críticos y reseñas literarias (1904-1905) ${ }^{66}$.

60 Beatriz González, Andrés de Santa María (1860-1945): Un precursor solitario (Bogotá: Museo Nacional de Colombia, 1998), 11.

61 González, Andrés de Santa María (1860-1945),12.

62 Ibid., 16-17.

63 Beatriz González, Andrés de Santa María (1860-1945): Un precursor solitario (Bogotá: Museo Nacional de Colombia, 1998), 21-23.

64 González, Andrés de Santa María (1860-1945), 24.

65 Rafael Gutiérrez Girardot, "Tres revistas colombianas de fin de siglo.” Boletín Cultural y Bibliográfico 28.27 (1991): 11-12.

66 Girardot, “Tres revistas colombianas de fin de siglo.”, 11. 
Las obras de Santa María fueron "revolucionarias" con respecto a los otros trabajos exhibidos dentro de la Feria, motivo por el cual no solo llamaron la atención de los críticos de arte, sino del público en general. Según algunos artículos de prensa, las personas comentaban constantemente sobre el estilo "particular" del "extranjero", ya que no agradaba por la falta de parecido con la realidad ${ }^{67}$. Igualmente, las personas no se sentían cómodas con el manejo del color. Por ello, sus obras fueron descritas como "pinturas extrañas" ${ }^{68}$. El estilo de Santa María no solo estaba en contra de los cánones estéticos de la Academia de Bellas Artes, por ende, de las nociones de belleza de las élites culturales del país, sino que eran expresiones de su propia creatividad como artista.

En otras palabras, este no imitó ningún tipo de corriente en particular, ya que yuxtapuso elementos tanto técnicos como visuales de las diferentes propuestas artísticas predominantes. Un ejemplo de ello es el cuadro de Los Fusileros (1885), puesto que Santa María utiliza aspectos del Impresionismo para dar movimiento y sensación de instancia a las bayonetas, pero también utiliza elementos académicos, tanto en la elección de la temática como en la distribución de la composición. De ese modo, los críticos de arte empezaron a ofrecer sus opiniones al respecto.

No obstante, entre las réplicas es posible señalar que la problemática real era la incapacidad de comprensión y clasificación de las obras, según los criterios evaluativos locales. Así pues, en 1904 Sanín Cano inicia su artículo indicando que no es una crítica de arte, por el contrario, son breves reflexiones sobre la obra de Santa María y su relevancia dentro del desarrollo de las artes en Colombia. A lo largo de la publicación, este define el Impresionismo y sus características centrales. Sin embargo, expresa su frustración al no poder comprender del todo la obra. Al parecer, sufre de un "pobre vocabulario para determinar aquello que observo en la exposición"69. Simultáneamente, manifiesta que las personas rechazan las corrientes modernistas, como el Impresionismo, pues los artistas no cumplen con sus expectativas.

Por ello, Sanín Cano defiende la obra de Santa María al argumentar que el arte no necesariamente debe representar con exactitud la naturaleza. Para él, el verdadero arte es aquel que hace "hermosura" ${ }^{70}$. Aquel argumento es reprobado por el crítico de arte Max Grillo en 1905, pues según este, el buen arte no tiene relación con lo hermoso. Por el contrario, el arte legítimo es aquel que logra emocionar, pues contiene el alma y las emociones del artista. Solo el arte que ofrece emoción puede ser denominado Bello ${ }^{71}$. En ese sentido, Grillo afirma que la obra de Santa María no es buena,

67 Francisco Cano, “Andres Santa María” Lectura y Arte 1(1903): 13-14.

68 Francisco Cano, "Andres Santa María”, 13-14.

69 Baldomero Sanín, "El impresionismo en Bogotá" Revista Contemporánea 1, 2 (1904): 145-156.

70 Sanín, "El impresionismo en Bogotá", 145-156.

71 Max Grillo, "Psicología del impresionismo" Revista Contemporánea 2,1 (1905): 32-37. 
independientemente de su técnica o manejo del color, ya que no transmite nada ${ }^{72}$. Para este crítico, los cuadros son vacíos, ya que el Impresionismo solo retiene momentos, por ende, no tienen larga vida.

Ese mismo año, Sanín Cano responde a Grillo, señalando que su intención no era elaborar una crítica de arte y mucho menos determinar si la obra de Santa María era buena o no. Según Sanín Cano, este solo pretendía dar su opinión frente a un artista. Es importante resaltar que Cano plantea que Grillo solo le respondió, ya que este no era un artista o crítico de arte "profesional"73. En esa medida, es posible asegurar que los críticos de arte, al parecer, eran los únicos autorizados para opinar sobre este tipo de debates culturales a nivel nacional. Así mismo, el ser crítico de arte era una posición posiblemente privilegiada en términos sociales, lo cual permite asumir la posible existencia de grupos restringidos de críticos. En resumen, Cano mantiene su posición al indicar que la emoción de Santa María no sólo era visible en sus cuadros, sino en las obras de sus estudiantes. Además, reafirma la imposibilidad de entender dichos cuadros.

Finalmente, Ricardo Hinestrosa Daza contesta a la controversia apoyando a Max Grillo, pues una obra sin emoción simplemente es nada. De igual modo, este sostiene que la emoción es uno de los elementos más esenciales dentro de la pintura. Por ello, para Hinestroza la obra de Santa María practicamente es carente de espíritu, por ende, este no puede ser considerado un artista ${ }^{74}$. A partir de estos artículos es posible llegar a una definición de arte y un nuevo horizonte de expectativa. De esa manera, estos críticos de arte ofrecen una conceptualización indirecta sobre que se tenía que entender por arte. En términos generales, el Arte es toda producción humana que logre emocionar a un público, sin que dicha producción responda a una serie de estándares o tendencias artísticas particulares.

En cuanto a la definición de artista, este viene siendo aquel genio creador que logra transmitir dentro de sus obras una cierta emoción relacionada con sus propios sentimientos y pensamientos. En esa medida, la técnica, la maestría y la destreza vienen siendo elementos secundarios, pues no aseguran una verdadera experiencia estética. Lo anterior es llamativo, pues al parecer los críticos de arte a finales del siglo XIX, evaluaron con base en nociones abstractas y subjetivas relacionadas al gusto personal. En otras palabras, una obra sólo era buena si era capaz de emocionar individualmente al crítico, sin importar que tipo de reacción o recepción que pudiera causar en un amplio público espectador.

Esta idea se logra reafirmar con la posición de Grillo, ya que al parecer la única opinión relevante es la del crítico de arte profesional, no sólo por ser la autoridad, sino

72 Grillo, "Psicología del impresionismo", 32-37.

73 Sanín, "El impresionismo en Bogotá" Revista Contemporánea 1, 2 (1904): 145-156.

74 Ricardo Hinestrosa, "El impresionismo en Bogotá” Revista Contemporánea 2, 3 (1905): 193-224. 
la única persona "capacitada" para dar juicios de valor verídicos. Entonces, resulta interesante pensar en la crítica de arte de finales del siglo XIX y comienzos del XX como un ejercicio de reflexión individual, pero con pretensiones de universalidad, en donde la opinión concreta de un crítico era incuestionable. Ahora bien, existe la posibilidad de que dicho entendimiento del "artista y su arte" solo haya sido aplicado o válido para este caso en específico, pues estos críticos de arte no comprendieron los cuadros de Santa Maria de un modo integral.

Es decir, todavía no habían herramientas útiles de análisis para la evaluación concreta de los cuadros, por tanto, se recurrió a la emoción como un calificativo alternativo y necesario para dar sentido a dichas obras de Santa María. Si no es posible calificar la técnica del artista, si era posible calificar la obra con base en la experiencia estética que esta proporciona al espectador. De esa manera, la crítica de arte de finales del siglo XIX se vio obligada a repensar conscientemente los ideales estándares de la Academia, dando inicio a una forzosa transición de paradigma artístico.

\section{Reflexiones finales: nuevos criterios y contradicciones}

Finalmente, se puede decir que la crítica de arte en Colombia a finales del siglo XIX, específicamente aquel periodo de transición entre el siglo XIX al siglo XX, estuvo caracterizada por la confusión y la apertura forzada a nuevas tendencias artísticas. En primer lugar, la "Polémica del Impresionismo" frente a la obra de Andrés de Santa María, en el fondo era una discusión por la posible introducción de nuevos cánones estéticos dentro del escenario plástico del país. En esa medida, la obra de este artista fue un medio para entrar a debatir cuestiones más complejas, entre ellas el limitado horizonte de expectativa y los términos evaluativos de estos críticos. Al parecer, la crítica capitalina tenía como punto de referencia el arte académico. Por ello, la calificación y evaluación del arte nacional solo era posible desde las restricciones de dicho estilo.

En esa medida, una obra "modernista" o con rasgos diferenciales a la corriente académica no podía ser interpretada en su totalidad e integridad. En el caso de los cuadros de Santa María, su trabajo no fue comprendido e incluso puede que haya sido menospreciado a partir de querellas que aludían a la "emoción" y no a cuestiones como la técnica o destreza del artista. Esto tiene sentido, pues, los críticos de arte se limitaron a mencionar elementos superficiales de los cuadros, ya que no tenían categorías analíticas suficientes y efectivas para leer dichas pinturas. Por lo tanto, estos críticos se vieron obligados a expandir sus criterios de evaluación y repensar hasta el propósito del arte. Esto con el fin de ubicar y dar sentido a aquello que no habían visto con anterioridad.

En segundo lugar, los críticos de arte, al enfrentarse a estas nuevas tendencias modernistas, también se vieron presionados e incluso obligados a entablar un diálogo 
con sus colegas. De ese modo, buscaron un consenso sobre las distintas interpretaciones posibles de aquella nueva propuesta. Así pues, se puede decir que una de las consecuencias más evidentes de la ruptura del canon academicista es el dinamismo de la crítica. En otras palabras, se dejan los comentarios aislados para comenzar debates públicos entre autoridades, en donde sea posible configurar un nuevo horizonte de expectativa para las próximas tendencias artísticas del siglo XX. Ahora bien, es necesario precisar que la crítica capitalina no pensó en las implicaciones futuras de este tipo de arte. Sin embargo, sus discusiones crearon un precedente para la siguiente generación de críticos.

Por último, estos críticos de arte abrieron dos paradojas dentro de la prensa cultural capitalina. La primera hace alusión a la clasificación de la obra de Andrés de Santa María como “impresionista”, pues sus cuadros tenían elementos tanto académicos como modernos. Por ello, se puede decir que dicha categorización fue un juicio apresurado, ya que a partir de traducciones y elementos teóricos creyeron haber visto un representante de aquella corriente. Los críticos distinguieron la obra de Santa María sin fijarse en el sentido completo de la composición, sólo revisaron algunos rasgos para direccionar sus hipótesis y argumentos. En cuanto a la segunda contradicción, se puede mencionar que el sentido general del arte colombiano de finales del siglo XIX respondía a la necesidad de mostrar y encarnar un progreso cultural dentro del Estado-nacional.

Así pues, el arte daba cuenta de aquellos cambios culturales en la mentalidad de los artistas. No obstante, la crítica en vez de promover dichas transformaciones las juzgó desde su propia diferencia con respecto al arte académico. Por tanto, es posible observar como un medio que debería estar dispuesto a profesar modernidad y desarrollo trataba de mantenerse fijo en sus convicciones académicas de periodos pasados. En conclusión, la reacción de los críticos de arte de Bogotá frente a la introducción de tendencias modernistas en el país fue negativa, puesto que no había un lenguaje, criterio o punto de referencia que ayudará a la asimilación de dichas nuevas corrientes artísticas.

\section{Bibliografía}

Arenas, Claudio Godoy. "Semiótica y teoría de la recepción: Los estudios literarios según Umberto Eco." UCMAULE - Revista Académica de la Universidad Católica del Maule no. 43 (2012): 27-39.

Badawi, Halim. Historia URGENTE del arte en Colombia. Dos siglos de arte en el país. Bogotá: Editorial Planeta Colombiana, S.A., 2019. 
Burke, Peter. Visto y no visto: el uso de la imagen como documento histórico. London: Reaktion Books, Ltd., 2001.

Cabrera, Eugenio Barney. "Reseña del arte en Colombia durante el siglo XIX". Anuario Colombiano de Historia Social y de la Cultura 3 (1965): 71-118.

Cano, Francisco. “Andres Santa María” Lectura y Arte 1 (1903): 13-14.

Catelli, Laura. "Pintores criollos, pinturas de castas y colonialismo interno: los discursos raciales de las agencias criollas en la Nueva España del periodo virreinal tardío". Cuadernos del CILHA 13, 2. (2012): 146 - 174.

Dickie, George. Evaluating Art, Filadelfia: Temple University Press, 1988.

González, Alberto. "En torno a la crítica de Arte". Revista de extensión cultural 32-33 (1994): $14-25$

González, Beatriz. Andrés de Santa María (1860-1945): Un precursor solitario. Bogotá: Museo Nacional de Colombia, 1998.

González Casanova, Pablo. La teoría marxista hoy. Problemas y perspectivas. Buenos Aires: Consejo Latinoamericano de Ciencias Sociales. CLACSO, 2006.

Grillo, Max. "Psicología del impresionismo" Revista Contemporánea 2, No.1 (1905): 32-37.

Gutiérrez Girardot, Rafael. "Tres revistas colombianas de fin de siglo.” Boletín Cultural y Bibliográfico 28.27 (1991): 2-17.

Hinestrosa, Ricardo. "El impresionismo en Bogotá" Revista Contemporánea 2, No.3 (1905): 193-224.

Jaramillo, Carmen María. "Una mirada a los orígenes del campo de la crítica de arte en Colombia". Artes: La Revista, 7 (2004): 3-38.

Jiménez, David. Historia de la crítica literaria en Colombia. Bogotá: Universidad Nacional de Colombia y Colcultura, 1992. 
Ladino Becerra, Rubén Darío. "Primeros años de la Escuela Nacional de Bellas Artes de Colombia". Tesis de maestría. Pontificia Universidad Javeriana. 2015.

Londoño, Santiago. Pintura en America Hispana. Tomo II - Siglo XIX. Bogotá: Editorial Universidad del Rosario y Luna Libros, 2012.

Panofsky, E. Estudios sobre iconología. Madrid: Alianza Editorial,1998.

Quinche, Víctor. Andrés de Santa María en los críticos de arte colombianos. Bogotá: Editorial Universidad del Rosario, 2014.

—_."La crítica de arte en Colombia: los primeros años." Historia Crítica 32 (2006): 274-301.

Sanín, Baldomero. "El impresionismo en Bogotá" Revista Contemporánea 1, 2 (1904): 145-156.

Tinio, Pablo. "From Artistic Creation to Aesthetic Reception: The Mirror Model of Art." Psychology Of Aesthetics, Creativity \& The Arts 7, 3 (2013): 265-275. 